Portland State University

PDXScholar

\title{
Considering Health in US Metropolitan Long-Range Transportation Plans: A Review of Guidance Statements and Performance Measures
}

\author{
Patrick A. Singleton \\ Portland State University \\ Kelly J. Clifton \\ Portland State University, kclifton@pdx.edu
}

Follow this and additional works at: https://pdxscholar.library.pdx.edu/cengin_fac

Part of the Civil and Environmental Engineering Commons Let us know how access to this document benefits you.

\section{Citation Details}

Singleton, Patrick A. and Clifton, Kelly J., "Considering Health in US Metropolitan Long-Range Transportation Plans: A Review of Guidance Statements and Performance Measures" (2017). Civil and Environmental Engineering Faculty Publications and Presentations. 404.

https://pdxscholar.library.pdx.edu/cengin_fac/404

This Post-Print is brought to you for free and open access. It has been accepted for inclusion in Civil and Environmental Engineering Faculty Publications and Presentations by an authorized administrator of PDXScholar. Please contact us if we can make this document more accessible: pdxscholar@pdx.edu. 


\title{
Considering health in US metropolitan long-range transportation plans: A review of guidance statements and performance measures
}

\author{
Patrick A. Singleton ${ }^{\mathrm{a}, *}$, Kelly J. Clifton ${ }^{\mathrm{a}}$ \\ ${ }^{a}$ Department of Civil and Environmental Engineering, Portland State University, \\ PO Box 751-CEE, Portland, OR 97207-0751, US \\ * Corresponding author. Phone: +1-412-480-7685. \\ Email: patrick.singleton@pdx.edu (P. A. Singleton), kclifton@pdx.edu (K. J. Clifton)
}

\begin{abstract}
Transportation influences health primarily and most directly through traffic safety, air quality, physical activity, and accessibility. Despite the importance of all four components, only safety and air quality are typically considered during institutionalized transportation planning processes. This paper assesses how health impacts are considered in transportation planning by focusing on the long-range transportation plans that US metropolitan planning organizations develop. We analyzed the content of current plans from 25 large regions, reviewing how policy guidance statements and supporting performance measures addressed health. Goals and objectives exhibited an incomplete perspective of transportation's effects on health, focusing on safety, accessibility, and air quality, neglecting physical activity. Regional policies reflected national goals and planning requirements, which are rarely framed from a health perspective. Performance measures generally followed policy guidance, although measures of health and physical activity were lacking. Increased attention to the development of health-related performance measures and the data and analysis tools to support them is needed. By assessing the state of the practice and discussing potential approaches, this review informs a stronger and more comprehensive consideration of health within the institutionalized structure of US metropolitan transportation planning.
\end{abstract}

\section{Keywords}

health; transportation planning; traffic safety; air quality; physical activity; accessibility

\section{Published as:}

Singleton, P. A., \& Clifton, K. J. (2017). Considering health in US metropolitan long-range transportation plans: A review of guidance statements and performance measures. Transport Policy, 57, 79-89. https://doi.org/10.1016/j.tranpol.2017.02.003 


\section{Introduction}

Health, the physical health and overall wellness of a person or population, is directly influenced by transportation systems and policies in several critical ways, including through traffic safety, air quality, physical activity, and accessibility. Traffic collisions can cause minor to severe injuries and fatalities (Cohen et al., 2009); there were over 32,000 deaths and 2.3 million injuries from traffic crashes in the US in 2014 (NHTSA, 2016). Emissions produced from the operation of motor vehicles pollute air and lead to adverse health impacts (HEI, 2010), including respiratory illnesses like asthma, afflicting nearly 8\% of Americans (CDC, 2016). Walking and bicycling provide physical activity that affords potentially significant health benefits (Handy, 2009), considering that more than one-third of US adults are obese (Odgen et al., 2014). Transportation systems facilitate access to healthy opportunities like education, employment, food, health care, social services, and recreation (Malekafzali, 2009). Together with noise pollution, mental health, and social equity, these aspects-traffic safety, air quality, physical activity, and accessibility-constitute a comprehensive view of the connections between transportation and health (APHA, 2009; Bell and Cohen, 2009b; CDC, 2014; FHWA, 2014; Litman, 2013).

Because transportation systems and policies have such broad impacts on personal and population-level health, many public health and transportation advocates, professionals, and agencies have argued that health impacts should be considered within transportation policymaking and planning processes (APHA, 2009; Bell and Cohen, 2009a; FHWA, 2014). These calls could be viewed from within the context of changing and widening goals for transportation at the federal, state, regional, and local levels in the US (Handy, 2008). Transportation planning has shifted from a focus on providing mobility (or reducing congestion) and increasing safety to considering (often competitive) economic, environmental, equity, and other goals (Weiner, 2013), including health. Changes in US federal transportation legislation mean a greater emphasis in transportation planning on economic vitality, security, environmental protection, intermodalism, operational efficiency, system preservation, resiliency, and tourism (SAFETEALU, 2005; MAP-21, 2012; FAST Act, 2015). As an “emerging” topic (Lyons, 2014), transportation's impacts on health are mentioned only indirectly in federal legislation, through safety, accessibility, and general quality of life.

One way for US transportation planning practices to more strongly consider impacts on health is through the regional or long-range transportation plans (LRTPs) that metropolitan planning organizations (MPOs) must develop every four to five years (USDOT, 2007). About 250 million people, or about 80\% of the entire US population (as of 2010), live in areas covered by MPOs (USDOT, 2014). In LRTPs, MPOs identify regional transportation investments over the next two decades, an appropriate temporal scale for considering health since many of transportation's health impacts are felt over multiple years or the course of individual lifetimes. If planning documents and directives take health impacts into account, healthier transportation projects and improved health outcomes may be more likely to result. Two major components of LTRPs warrant closer scrutiny for health consideration: what we call guidance statements and performance measures.

We define guidance statements as the high-level transportation policy language used to guide the development of a plan, such as the vision, goals, objectives, and strategies. A vision statement lays out the plan's overarching purpose. Goal statements describe the region's desired future. Specific objectives - measurable outcomes of the plan or the transportation system- 
usually accompany goals. Strategies or actions to accomplish the objectives may also be included. Together, these guidance statements are intended to frame the plan, influence the selection of transportation investments, inform project prioritization, and be the statements against which to assess the success of the plan (Handy, 2008; Grant et al., 2014; Pickrell and Neumann, 2001). High-level language is often developed by MPO boards and vetted through public comment. If included, health-related guidance statements may compete with or synergize other transportation policy goals.

Performance measures are quantitative or qualitative metrics used to assess plan performance. Many MPOs have begun to incorporate performance measures into their LTRPs (Handy, 2008; Peckett and Duffy, 2012) so that decision-makers can better analyze current conditions, select projects, assess plan performance, and monitor progress toward plan goals. Adequate and appropriate measures are central to performance-based planning (Cambridge Systematics, 2000). Theoretically, performance measures should be developed to fit established objectives, rather than selecting goals to fit the limited scope of what can be measured (Grant et al., 2013, 2014; Pickrell and Neumann, 2001); however, data limitations, forecastability, and ability to influence also shape the selection of measures (Grant et al., 2013). Although they may be difficult to forecast and affect, health-related performance measures can be developed.

A critical requirement for all other performance measures, especially quantitative ones, is the existence of data and supporting analytical methods (Pickrell and Neumann, 2001). Traditionally, travel demand forecasting models and their extensions supply estimates that can be used for performance measurement. For example, travel model outputs such as vehicle miles traveled or number of walking and bicycling trips can be converted into estimates of air pollution and physical activity, the health impacts of which could be approximated using post-processing tools and models (EPA, 2014; Woodcock et al., 2009; WHO, 2014).

The guiding framework for our study of health in MPO LRTPs is the following perspective. In an “ideal” transportation planning process, a plan's guidance statements would reflect all critical collective regional goals and objectives (including health); and, each of those goals would be assessed by specific performance measures, with support from data and analytical tools like travel models. For example, a region interested in increasing health via active transportation could include a plan goal to "increase physical activity levels", informed by a performance measure of "minutes of daily walking/bicycling per capita”, further supported by improvements in how the regional travel model forecasts walking and bicycling trips (Singleton and Clifton, 2013). Other researchers have used similar perspectives when focusing on goals/objectives and performance measures in metropolitan transportation planning (Handy, 2008; Lee and Sener, 2016; Manaugh et al., 2015). Certainly, the final decision about whether and how to include health-related statements and measures must be made by MPO boards, informed by staff, expert, and public input. The fact that many MPOs are interested in more comprehensively considering health in transportation planning motivates our work.

\section{1. $\quad$ Research questions and hypotheses}

Our fundamental goal is to understand and analyze how health and transportation intersect in metropolitan transportation planning and policy-making. Based on the discussion above, we focus our efforts on investigating health consideration within specific parts of the long-range transportation plans of large MPOs. Nearly two-thirds of people served by MPOs reside within large MPOs (those with more than one million people) (USDOT, 2014). These 
organizations often have bigger budgets and more advanced technical capabilities, which can be useful for analyzing transportation's health impacts. We perform a content analysis of the guidance statements and performance measures contained in 25 large MPO plans. Our research attempts to provide insight into the following key questions:

- What is the state of the practice of considering health in MPOs' LRTPs?

- How is health framed in plans' guidance statements?

- How is health represented in plans’ performance measures?

- How are health-related statements connected to health-related measures?

o To what extent are physical activity statements and measures related to travel demand forecasting model capabilities for analyzing walking and bicycling?

We anticipate that health will be incompletely represented, with some componentsparticularly safety and air quality_reflected in goals and objectives but fewer included in measures. Regions with strong or comprehensive health-related guidance statements are expected to have more established health-related performance measures. We also may find that regions using physical activity measures also have stronger analytical capabilities for modeling walking and bicycling. While we assume that regions with plans that include health-related statements and measures will therefore prioritize and build healthier transportation projects, this remains an open question that must be left for future work.

Our paper is organized as follows. First, the Background section presents a brief summary of how health impacts have been historically considered within transportation planning processes. Then, we describe our content analysis of specific MPO LRTPs within the Method section. Next, the Results section presents the health-related guidance statements and performance measures found from our content analysis. Finally, a Discussion section summarizes our key findings, discusses potential strategies for more-strongly considering health in transportation planning, and notes study limitations and opportunities for future research.

\section{Background}

Focusing on health-related issues in transportation is not a new concept; consider traffic safety. Since nearly the beginning of the automobile age, the threats of injuries and fatalities from traffic collisions have driven improvements to vehicle occupant safety and promoted traffic safety as the motivating objective in street and highway design, for better and for worse (Norton, 2008). Road projects have long been advanced on the basis of their potential to reduce traffic collisions, and the Highway Safety Manual (AASHTO, 2010) formalizes the estimation of crash frequencies and severities and the selection of countermeasures. Recent recommendations document how to consider safety in transportation planning, such as including safety goals and performance measures in a long-range plan (Washington et al., 2006).

Air quality, while also not a recent concern, has found its way into formal transportation planning processes since at least the National Environmental Policy Act of 1969 (NEPA, 2012). The Clean Air Act Amendments of 1990 (CAAA, 2012) require MPOs in poor air quality (nonattainment or maintenance) areas to demonstrate that their transportation plans conform to requirements designed to allow states to comply with national ambient air quality standards (Howitt and Moore, 1999). The institutionalized nature of air pollution analysis has led to a 
strong focus on air quality in LRTPs. With no similar mandate, the physical activity and accessibility components of public health have not been as widely considered in transportation planning goals, policies, and official documents.

Environmental justice (EJ) is another area with federally-mandated regional planning requirements related to health. Under Title VI of the Civil Rights Act and Executive Order 12898, MPOs must identify and address "disproportionately high and adverse human health or environmental effects" of their transportation plans on minority and low-income populations (E.O. 12898, 1994). Relevant effects include social, economic, and environmental effects (Cambridge Systematics, 2002). Although health concerns are central to EJ, there are challenges to addressing direct health impacts in transportation EJ analyses. While region-wide measures typically focus on transit service, accessibility, and economic effects, safety and air quality impacts may only be considered for specific projects, if at all (Cambridge Systematics, 2002; Forkenbrock and Sheeley, 2004). When health effects are examined, data inputs and travel model outputs may be insufficient to analyze impacts by income or racial/ethnic user groups (Duthie et al., 2007). Finally, the priorities of EJ and community health advocates often differ from or even conflict with regional transportation goals (Deakin, 2007; McAndrews and Marcus, 2014).

Despite these challenges, metropolitan transportation planning practices are beginning to examine health more comprehensively (Burbidge, 2010). The U.S. Department of Transportation established a Health in Transportation Working Group to identify how federal efforts, including planning, might consider health (FHWA, 2014). Regarding analysis, health impact assessments (HIAs) are increasingly used to analyze potential health effects of significant projects, programs, and policies (Dannenberg et al., 2014; Ingles, 2013), including Atlanta's regional transportation plan (Ross et al., 2012). HIAs have also been conducted for some California MPOs (Garibay \& Seaton, 2014) when developing required Sustainable Communities Strategies in their plans. Other MPOs include public-health related goals in their LRTPs (Ingles, 2013).

In particular, the health benefits of physical activity are generating increased attention to active transportation policies and plans. Some federal and state funds may now be spent more flexibly and on walking and bicycling modes (Handy and McCann, 2011; Handy et al., 2009). Many state and local governments have adopted Complete Streets policies that require projects to accommodate all road users. Agencies at different levels are developing active transportation plans (ATPs) to encourage walking and bicycling and to coordinate non-motorized facility investments. Many ATPs include one or more health-related goals (Evenson et al., 2012). Some MPOs are even making their ATPs a component of their LRTPs (Handy and McCann, 2011; Metro, 2014). Analytical methods are improving MPOs' abilities to forecast walking/bicycling demand (Singleton and Clifton, 2013) in support of physical activity performance measures and health impact assessments.

The Volpe Center recently investigated case studies and best practices for how MPOs can consider health in many stages of regional transportation planning (Lyons et al., 2012). Through interviews and plan document reviews, the authors investigated work done by leading MPOs in Nashville, Sacramento, San Diego, and Seattle. In each case, they identified:

- motivations for initially expanding traditional planning concerns to include health;

- $\quad$ specific transportation planning process stages at which health was considered;

- early actions within existing structures that indicated an interest in health; and

- $\quad$ structural changes that resulted in stronger and lasting health considerations. 
The study identified several key themes: (a) forming partnerships with local and state public health organizations; (b) building support to consider health from MPO boards and the public; (c) developing internal and external capacity for quantitative health assessment; and (d) using an incremental approach to incorporate health concerns without sacrificing other planning functions (Lyons et al., 2012). The Volpe Center also completed a companion report looking at health in statewide transportation planning (Lyons et al., 2014).

The two Volpe Center reports demonstrate a wide range of actions and stages in which health can be considered in metropolitan transportation planning processes. Just because health may not be articulated within an MPO’s LRTP does not preclude that agency from making strides in a range of other activities, from outreach and interagency communication to project evaluation. Yet, the reports note important areas in which to accomplish structural changes: the guidance statements and performance measures contained within MPO plans (also, the focus of this study).

\section{Method}

We reviewed the long-range transportation plans from several large metropolitan planning organizations for indicators of health concerns. To examine differences in practice, 25 of the 48 largest MPOs (each covering a population greater than one million in 2010) were nonrandomly selected. Collectively, the selected MPOs serve over 100 million people, about a third of the US population and more than two-thirds of the population in the largest MPOs (USDOT, 2014). In the selection process, our objectives included geographic coverage (all regions in the US) and variety in population size (at least within large MPOs). Because of our secondary interest in connecting physical activity guidance statements and performance measures to walk/bicycle modeling capabilities, we also selected at least seven MPOs from each of three groups, related to a previous study of regional travel demand models (Singleton and Clifton, 2013): MPOs with tier I models that do not include walking or bicycling; MPOs with tier II models that group walking and bicycling into a single non-motorized mode; and MPOs with tier III models that include both walking and bicycling in the mode choice stage. The most recentlyadopted LRTPs (through August 2015) for each of the 25 MPOs were gathered from respective agency websites. Table 1 shows the subject MPOs, information about the LRTPs, and walk/bicycle modeling abilities. Plans were adopted 2010 to 2015; since plans typically take 2+ years to develop, planning processes were likely initiated around 2008-2013. Plan horizon years were 2035, 2040 (typically), or 2045.

After obtaining plan documents, we performed a content analysis on the text data using electronic searches for health-related terms. The method was a mix of directed and summative content analyses, in which specific predetermined keywords were used to identify and code passages of interest (Hsieh and Shannon, 2005). The Volpe Center metropolitan report (Lyons et al., 2012) and the Portland MPO's LRTP were used to develop the list of screening and search terms and to pilot the health content analysis. Other analyses of MPO planning documents have used similar search techniques (Handy, 2008; Lee and Sener, 2016; Manaugh et al., 2015).

Two areas of the LTRPs were of particular interest: guidance statements and performance measures. As previously mentioned, guidance statements are the high-level overarching transportation policy language used to guide plan development. The following search terms were used to identify guidance statements: “vision”, “goal”, “objective”, “principle”, “policy”, 
"strategy", "recommendation", and "outcome”. On the other hand, performance measures are specific metrics used to assess plan performance. The following search terms were used to identify performance measures: “performance”, "measure”, “metric”, “indicator”, "factor”, "standard”, and "target”. Each entire LRTP document was also visually scanned to ensure that all relevant sections were found.

After identifying a plan's guidance statements and performance measures, these items were filtered by their concern for health. The health content analysis was framed around references to health in general and to four primary components of transportation-related health impacts: traffic safety, air quality, physical activity, and accessibility. Of course, there may have been other indirect ways in which plans addressed impacts on health not captured within these four areas. However, identifying implicit mentions of health is a more difficult and subjective task, and our focus was on explicit expressions of health considerations. Other researchers have analyzed how equity, quality of life, and related issues are addressed in transportation plans (Handy, 2008; Karner and Niemeier, 2013; Lee and Sener, 2016; Manaugh et al., 2015; Martens et al., 2012).

Statements reflecting a general consideration of health had to include the term "health" and contextually reflect an intention to mean "human”, "population”, or "public” health instead of "environmental" or "economic" health. Safety statements needed to include one of the terms "safe” or "safety”. Statements about air quality referred to "air quality”, "air pollution”, or "emissions" and not just a concern for "the environment”. Physical activity statements had to include the phrase "physical activity" or mention "health" in relation to walking and bicycling. Accessibility statements typically used the words “access”, “connect”, or "opportunity”. General health performance measures had to be a direct health outcome like obesity rather than a health indicator like levels of physical activity. Other health-related measures were classified by their connection to guidance statements and by context.

\section{4. $\quad$ Results}

Many health guidance statements and performance measures were identified in the review of MPO LRTPs. Table 1 documents the 25 plans analyzed, while Table 2 displays the presence of health-related statements and measures. Figure 1 summarizes the results of Table 2 in graphical form. 
TABLE 1 Information about MPOs and their long-range transportation plans

\begin{tabular}{|c|c|c|c|c|c|}
\hline Region & Metropolitan planning organization (MPO) & $\begin{array}{c}2010 \\
\text { pop. } \\
(M)\end{array}$ & $\begin{array}{l}\text { Plan } \\
\text { year }\end{array}$ & $\begin{array}{r}\text { Horizon } \\
\text { year }\end{array}$ & $\begin{array}{r}\text { Walk } \\
\text { \& bike } \\
\text { models }^{\mathrm{a}} \\
\end{array}$ \\
\hline Atlanta, GA & Atlanta Regional Commission & 4.8 & 2014 & 2040 & II \\
\hline Baltimore, MD & Baltimore Regional Transportation Board & 2.7 & 2011 & 2035 & II \\
\hline Boston, MA & Boston Region Metropolitan Planning Organization & 3.2 & 2015 & 2040 & III \\
\hline Chicago, IL & Chicago Metropolitan Agency for Planning & 8.4 & 2014 & 2040 & II \\
\hline Cleveland, $\mathrm{OH}$ & Northeast Ohio Areawide Coordinating Agency & 2.1 & 2013 & 2035 & III \\
\hline Denver, CO & Denver Regional Council of Governments & 2.8 & 2011 & 2035 & III \\
\hline Detroit, MI & Southeast Michigan Council of Governments & 4.7 & 2013 & 2040 & I \\
\hline Houston, TX & Houston-Galveston Area Council & 5.9 & 2015 & 2040 & I \\
\hline Kansas City, MO & Mid-America Regional Council & 1.9 & 2015 & 2040 & $\mathrm{I}$ \\
\hline Las Vegas, NV & Regional Transportation Commission of Southern Nevada & 2.0 & 2013 & 2035 & I \\
\hline Los Angeles, CA & Southern California Association of Governments & 18.1 & 2012 & 2035 & III \\
\hline Memphis, TN & Memphis Urban Area Metropolitan Planning Organization & 1.1 & 2012 & 2040 & II \\
\hline Miami, FL & Miami-Dade Metropolitan Planning Organization & 2.5 & 2014 & 2040 & III \\
\hline Milwaukee, WI & Southeastern Wisconsin Regional Planning Commission & 2.0 & 2014 & 2035 & II \\
\hline Nashville, TN & Nashville Area Metropolitan Planning Organization & 1.4 & 2010 & 2035 & I \\
\hline New York, NY & New York Metropolitan Transportation Council & 12.4 & 2013 & 2040 & II \\
\hline Orlando, FL & MetroPlan Orlando & 1.8 & 2014 & 2040 & I \\
\hline Phoenix, AZ & Maricopa Association of Governments & 4.1 & 2014 & 2035 & I \\
\hline Pittsburgh, PA & Southwestern Pennsylvania Commission & 2.6 & 2011 & 2040 & I \\
\hline Portland, $\mathrm{OR}^{\mathrm{b}}$ & Metro & 1.5 & 2014 & 2040 & III \\
\hline San Antonio, TX & Alamo Area Metropolitan Planning Organization & 2.0 & 2014 & 2040 & III \\
\hline San Francisco, CA & Metropolitan Transportation Commission & 7.2 & 2013 & 2040 & III \\
\hline Seattle, WA & Puget Sound Regional Council & 3.7 & 2014 & 2040 & III \\
\hline St. Louis, MO & East-West Gateway Council of Governments & 2.6 & 2015 & 2045 & III \\
\hline Washington, DC & National Capital Region Transportation Planning Board & 4.6 & 2014 & 2040 & II \\
\hline
\end{tabular}

a Tier I models do not include walking or bicycling. Tier II models group walking and bicycling into a single nonmotorized mode. Tier III models include both walking and bicycling in the mode choice stage.

b Portland, OR, was used to develop the screening and search terms. 
TABLE 2 Health concerns in MPO long-range transportation plans

\begin{tabular}{|c|c|c|c|c|c|c|c|c|c|c|}
\hline \multirow[b]{3}{*}{ MPO region } & \multicolumn{5}{|c|}{ Guidance statements } & \multicolumn{5}{|c|}{ Performance measures } \\
\hline & \multirow{2}{*}{$\begin{array}{c}\text { General } \\
\text { health }\end{array}$} & \multicolumn{4}{|c|}{ Health components } & \multirow{2}{*}{$\begin{array}{l}\text { General } \\
\text { health }\end{array}$} & \multicolumn{4}{|c|}{ Public health } \\
\hline & & Safety & Air & Activity & Access & & Safety & Air & Activity & Access \\
\hline Atlanta, GA & $\checkmark$ & $\checkmark$ & & $\checkmark$ & $\checkmark$ & $\checkmark$ & $\checkmark$ & $\checkmark$ & $\checkmark$ & $\checkmark$ \\
\hline Baltimore, MD & $\checkmark$ & $\checkmark$ & $\checkmark$ & $\checkmark$ & $\checkmark$ & & $\checkmark$ & $\checkmark$ & & $\checkmark$ \\
\hline Boston, MA & $\checkmark$ & $\checkmark$ & $\checkmark$ & $\checkmark$ & $\checkmark$ & - & - & - & - & - \\
\hline Chicago, IL & $\checkmark$ & $\checkmark$ & & & $\checkmark$ & & & & & $\checkmark$ \\
\hline Cleveland, $\mathrm{OH}$ & $\checkmark$ & $\checkmark$ & & & $\checkmark$ & - & - & - & - & - \\
\hline Denver, CO & & $\checkmark$ & $\checkmark$ & & $\checkmark$ & - & - & - & - & - \\
\hline Detroit, MI & & $\checkmark$ & & $\checkmark$ & $\checkmark$ & & $\checkmark$ & $\checkmark$ & & $\checkmark$ \\
\hline Houston, TX & $\checkmark$ & $\checkmark$ & $\checkmark$ & $\checkmark$ & $\checkmark$ & & $\checkmark$ & $\checkmark$ & $\checkmark$ & $\checkmark$ \\
\hline Kansas City, MO & $\checkmark$ & $\checkmark$ & $\checkmark$ & $\checkmark$ & $\checkmark$ & $\checkmark$ & $\checkmark$ & $\checkmark$ & $\checkmark$ & \\
\hline Las Vegas, NV & & $\checkmark$ & $\checkmark$ & & $\checkmark$ & - & - & - & - & - \\
\hline Los Angeles, CA & $\checkmark$ & $\checkmark$ & $\checkmark$ & $\checkmark$ & $\checkmark$ & $\checkmark$ & $\checkmark$ & $\checkmark$ & $\checkmark$ & $\checkmark$ \\
\hline Memphis, TN & $\checkmark$ & $\checkmark$ & $\checkmark$ & & $\checkmark$ & & $\checkmark$ & & & $\checkmark$ \\
\hline Miami, FL & & $\checkmark$ & $\checkmark$ & & $\checkmark$ & & $\checkmark$ & $\checkmark$ & & $\checkmark$ \\
\hline Milwaukee, WI & & $\checkmark$ & $\checkmark$ & & $\checkmark$ & - & - & - & - & - \\
\hline Nashville, TN & $\checkmark$ & $\checkmark$ & $\checkmark$ & $\checkmark$ & $\checkmark$ & - & - & - & - & - \\
\hline New York, NY & $\checkmark$ & $\checkmark$ & $\checkmark$ & & $\checkmark$ & - & - & - & - & - \\
\hline Orlando, FL & & $\checkmark$ & $\checkmark$ & & $\checkmark$ & & $\checkmark$ & $\checkmark$ & & $\checkmark$ \\
\hline Phoenix, AZ & & $\checkmark$ & $\checkmark$ & & $\checkmark$ & & $\checkmark$ & & & $\checkmark$ \\
\hline Pittsburgh, PA & $\checkmark$ & $\checkmark$ & & & $\checkmark$ & - & - & - & - & - \\
\hline Portland, OR & $\checkmark$ & $\checkmark$ & $\checkmark$ & $\checkmark$ & $\checkmark$ & & $\checkmark$ & $\checkmark$ & $\checkmark$ & $\checkmark$ \\
\hline San Antonio, TX & & $\checkmark$ & & & $\checkmark$ & & $\checkmark$ & & & $\checkmark$ \\
\hline San Francisco, CA & $\checkmark$ & $\checkmark$ & $\checkmark$ & $\checkmark$ & $\checkmark$ & $\checkmark$ & $\checkmark$ & $\checkmark$ & $\checkmark$ & $\checkmark$ \\
\hline Seattle, WA & $\checkmark$ & $\checkmark$ & $\checkmark$ & $\checkmark$ & $\checkmark$ & $\checkmark$ & & $\checkmark$ & $\checkmark$ & \\
\hline St. Louis, MO & & $\checkmark$ & $\checkmark$ & $\checkmark$ & $\checkmark$ & & $\checkmark$ & $\checkmark$ & $\checkmark$ & $\checkmark$ \\
\hline Washington, DC & & $\checkmark$ & $\checkmark$ & & $\checkmark$ & - & - & - & - & - \\
\hline Totals & 15 & 25 & 19 & 12 & 25 & 5 & 14 & 12 & 8 & 14 \\
\hline Percentages & $60 \%$ & $100 \%$ & $76 \%$ & $48 \%$ & $100 \%$ & $31 \%$ & $88 \%$ & $75 \%$ & $50 \%$ & $88 \%$ \\
\hline
\end{tabular}

- Performance measures were not included in plan.

a Portland, OR, was used to develop the screening and search terms. 


\section{Guidance Statements}

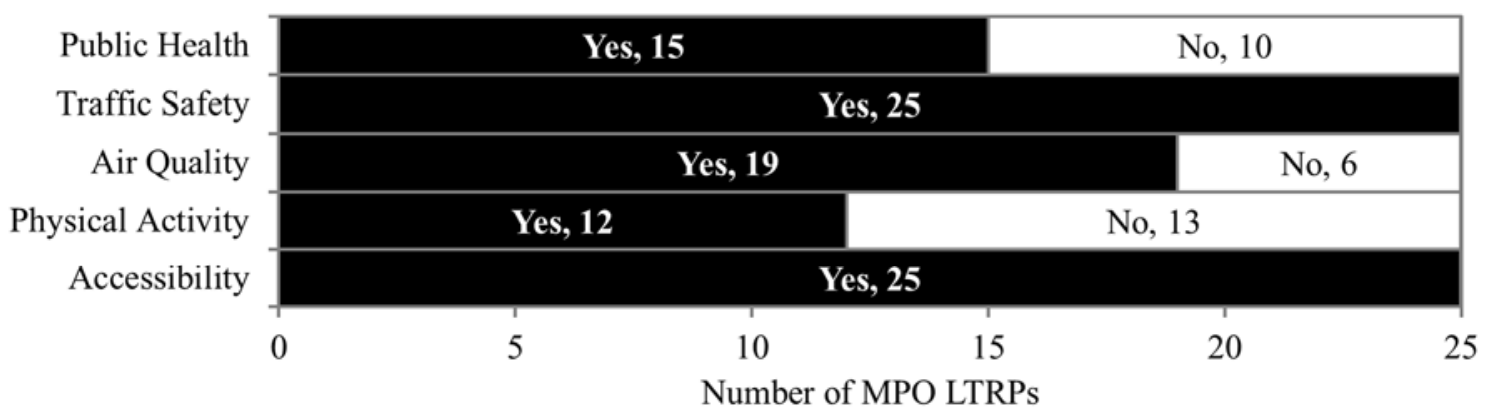

Performance Measures

\begin{tabular}{|c|c|c|c|}
\hline Public Health & Yes, 5 & No, 11 & No PMs, 9 \\
\hline Traffic Safety & Yes, 14 & No, 2 & No PMs, 9 \\
\hline Air Quality & Yes, 12 & No, 4 & No PMs, 9 \\
\hline Physical Activity & Yes, 8 & No, 8 & No PMs, 9 \\
\hline Accessibility & Yes, 14 & No, 2 & No PMs, 9 \\
\hline & 5 & $\begin{array}{cc}10 & 15 \\
\text { Jumber of MPO LRTPs }\end{array}$ & 20 \\
\hline
\end{tabular}

Figure 1 Summary of health-related guidance statements and performance measures.

\subsection{Health within guidance statements}

\subsubsection{General health}

Only 15 MPO plans specifically referenced "public health" or "human health" in their guidance statements. ("Ecological", "environmental", "fiscal”, and "economic" health language appeared more frequently. Statements referring to a more general "quality of life" did not qualify.) Some plans noted the "health of people" almost in passing within larger, more encompassing goals like "livability". Health was sometimes linked to other goals like environmental improvement and economic vitality. More often, health was one of a handful of plan goals. However, when "health" was an elaborated goal, plans tended to incompletely represent health, often focusing only on physical activity and/or air quality (Baltimore, Memphis, Nashville, New York). For instance, Los Angeles' plan “will have direct and substantial benefits to public health by reducing pollutant emissions and expanding the opportunities for active transportation”. Only the Portland and San Francisco plans' health goal were nearly as broad as possible, encompassing safety, air quality, and physical activity elements; e.g.,

Goal: Enhance Human Health. Multi-modal transportation infrastructure and services provide safe, comfortable and convenient options that support active living and physical activity, and minimize transportation-related pollution that negatively impacts human health (Portland). 


\subsubsection{Traffic safety}

All MPO plans included a safety goal or objective. Sometimes "improving safety" was a small part of broader language. More often, guidance statements emphasized the need for safe transportation systems for all users or all modes (Boston, Denver, Detroit, Las Vegas); e.g.,

Principle: Promote Safety and Security. Provide a safe and secure transportation system for all users. Safety throughout the system-for motorists, transit, emergency response, freight movement and non-motorized users such as bicyclists and pedestrians—should be a top priority in transportation planning (St. Louis).

Specific strategies to achieve safety goals, when identified, tended to be comprehensive. Baltimore's plan noted the need to reduce injuries and fatalities, develop safety-focused plans, improve high-crash locations, collect and analyze safety data, and improve emergency response. Regional plans also included other guidance, including suggestions for: street and intersection design improvements (Washington), especially at transit and intermodal locations (Miami); enhanced enforcement (Washington); more driver education (St. Louis); better safety data management (New York); policies like Complete Streets (Memphis); programs like Safe Routes to School (Miami); and training for emergency management and incident response (St. Louis).

\subsubsection{Air quality}

Nineteen MPO plans specifically called out air quality in policy guidance. Air quality references often fell within a broader "environmental" goal or were framed as an impetus for congestion reduction (Memphis). One plan emphasized a need to conform to state and federal air quality requirements (Milwaukee). Other plans did acknowledge the inherent human health benefits of reducing transportation-related emissions and pollution (Kansas City, Portland, San Francisco). For example, one aim in Baltimore's plan was to "enhance the quality of human health by providing multimodal transportation infrastructure and services that...minimize transportation-related emissions”. Some plans laid out specific strategies to accomplish air quality goals: e.g.,

Strategy: Support regional, state and federal programs which promote a costeffective combination of technological improvements and transportation strategies to reduce air pollution, including promoting use of transit options, financial incentives, and voluntary emissions reduction measures (Washington).

\subsubsection{Physical activity}

The plans of 12 MPOs included policies to increase physical activity. Vague plan language referring to walking and bicycling was included: e.g., "improving...personal health by facilitating walking [and] biking" (Detroit). Physical activity was more often an objective of the plan, rather than a goal. Many statements noted a need to promote communities and transportation systems that, for example, support and "encourage healthy lifestyles and active living for all ages” (Atlanta). A few plans specifically mentioned "physical activity” through bicycle and pedestrian and other multimodal options (Baltimore, Portland); e.g.,

Strategy: Promote active transportation. Active transportation systems should connect the places where people live, learn, work, shop and play with safe and 
convenient options for walking and bicycling. MARC and a number of local governments in the Kansas City region have adopted complete streets policies and bicycle, pedestrian and trail facility plans. Broader adoption and implementation of these types of policies and plans could increase opportunities for safe, active transportation and physical activity by children and adults (Kansas City).

\subsubsection{Accessibility}

Accessibility was the most frequent health component in guidance statements and was found in all plans. At the same time, it was sometimes nebulous and only tangentially-related to health. Accessibility statements were tied up with concepts of mobility, connectivity, and economic development. Some plans promoted access to unspecified "resources" or "desired destinations". Most emphasized access to places like "key activity population and employment centers" (Memphis), with specific improvement strategies such as jobs-housing balance (Seattle), coordinated land use and transportation planning (St. Louis), and reverse commutes using transit (St. Louis). Other specified destinations included services - educational institutions, libraries, restaurants, government and social agencies—and amenities—airports, museums, entertainment venues, arts and cultural facilities, and natural areas. Occasionally, policy guidance noted access to health-specific realms, including recreational opportunities (Detroit), health care facilities (Kansas City), and healthy food (Chicago).

Accessibility was frequently a justification for policy statements supporting public transit, walking, and bicycling (Atlanta, Denver, Nashville, St. Louis, Washington): e.g., "Improve access to and accessibility of transit and active modes" (Boston). Many guidance statements also noted unique access needs of specific populations, including children, students, older adults, people with disabilities, low-income communities, minority communities, transitdependent individuals, food desert residents, and other "persons with special accessibility needs" (Washington).

\subsection{Health-related performance measures}

\subsubsection{General health}

Only five MPO plans had a direct performance measure of population health (besides safety): the regional obesity rate (Atlanta, Kansas City), average body mass index (Seattle), asthma incidence (Los Angeles), and number of premature deaths due to fine particulates exposure (Los Angeles, San Francisco). While other plans' measures were related to general health policies, they were actually health proxies (e.g., walk/bike mode share, physical activity levels) and fit better within one of the following health components. Injury and fatality metrics could be considered direct health measures; but, as this is standard practice, they were included only in the safety category.

\subsubsection{Traffic safety}

When performance measures were used, MPO plans typically included safety ones. Most traffic safety measures were annual totals and/or average rates of traffic-related crashes, injuries, and/or fatalities. For example, Kansas City's plan had four safety performance measures: the total annual numbers of injuries and fatalities and the annual injury and fatality rates per 100 million vehicle miles traveled. Some plans also segmented measures by mode: walk, bicycle, and 
motor vehicle (Memphis, Portland). Unique safety performance measures were: incident response and clearance times (Atlanta, Houston, Portland), investment in safety projects (Miami), seat belt usage (Baltimore), and the presence of a Safe Routes to School program (Miami). Atlanta's plan noted the challenge of forecasting crashes and severities (especially fatalities) when evaluating the safety performance of future scenarios.

\subsubsection{Air quality}

Twelve MPO plans also contained air quality performance measures. Most air quality measures reflected the total weight of criteria pollutants emitted (usually from transportation sources) in the region, including ozone, particulate matter $\left(\mathrm{PM}_{2.5}\right.$ and $\left.\mathrm{PM}_{10}\right)$, carbon monoxide (CO), and nitrogen oxides ( $\mathrm{NO} \mathrm{x}$ ), sometimes averaged over a three-year period. For example, Baltimore's plan had four air quality measures: the total weights of volatile organic compounds, $\mathrm{NO}_{x}, \mathrm{CO}$, and $\mathrm{PM}_{2.5}$ emitted. Other less common air quality performance measures tracked time out of compliance with state and federal air quality standards (Seattle).

\subsubsection{Physical activity}

Only eight plans included physical activity performance measures, many from MPOs with Tier III walk/bicycle travel models. While some regions intended to track the obesity rate (using data from the Centers for Disease Control), most instead measured the number of walk, bicycle, and walk-to-transit trips (or mode shares) as a proxy for physical activity levels. Two plans (Los Angeles, San Francisco) specifically replaced a prior mode share measure with daily time spent in active transportation because it is more directly related to physical activity. Interestingly, only the Portland and San Francisco plans suggested using regional travel models to obtain this performance measure; other regions took commute mode shares from US Census data.

\subsubsection{Accessibility}

As with traffic safety, most MPO plans with measures included accessibility. Many different performance measures were associated with the wide range of accessibility guidance statements. Some plans gave undefined metrics, such as "reasonable access", "walking distance”, or "served by transit". More common accessibility measures fell into two categories: distancebased and time-based.

Distance-based measures assessed the proportion of residents or jobs located within a certain distance of a type of transportation facility, typically a "walkable" quarter or half mile from transit (or fixed-route/high-capacity transit). For example, Orlando's plan measured the percentages of population and employment within one quarter mile of transit service. Other facilities included trail access (Portland) and highway access to major activity centers, tourist attractions, and health, recreation, education, and cultural facilities (Miami).

In contrast, time-based accessibility measures assessed the proportion of population or employment located within a time threshold of people or jobs; Atlanta's plan included both. Thresholds typically varied by mode: e.g., 30 minutes by highways and 60 minutes by transit (Baltimore). Other regions incorporated innovative accessibility measures into plans, including jobs-housing balance (Orlando), joint housing-transportation affordability (Atlanta, San Francisco), sidewalk extent on urban state-owned roadways (Baltimore), and access to healthy food and to parks (Chicago). 


\section{Discussion}

Based on our content analysis and review of health in metropolitan long-range transportation plans, the following sections summarize key findings, discuss potential strategies for increasing the role of health in transportation planning practice, and note study limitations and opportunities for future work.

\subsection{Findings}

In general, our hypotheses were met: in most cases, health is incompletely considered within regional transportation planning. Just two plans (Los Angeles, San Francisco) contained guidance statements and performance measures in all categories of health (including a direct health measure). Goals and objectives emphasized safety, air quality, and accessibility more than physical activity. Health-related performance measures, while generally tied to guidance statements, were lacking for general health and physical activity. Based on our results, we can tentatively make some overall observations about how health is treated within MPO long-range plans, as elaborated below.

Plans often reflect an incomplete view of how transportation systems influence health. Only ten of the plans referred to all four health components within guidance statements. Even plans with overarching general health goals tended to describe "health" in terms of air quality and physical activity; others have also found this trend (Lee and Sener, 2016). MPO LRTPs have yet to fully adopt a holistic approach to linking transportation and health (Lyons et al., 2012).

Most plans are guided by safety concerns and a desire to increase accessibility. Nearly all MPO plans had safety and accessibility as important transportation goals, a finding echoed by other researchers (Lee and Sener, 2016). Yet, these goals — especially access-were often divorced from a public health perspective. Accessibility was promoted more from the points of view of equity and economic vitality than as a health concern. The considerations of safety and accessibility in isolation may reflect the lack of a comprehensive vision of health within transportation planning.

Air quality concerns may be under-represented in this analysis. Although only threequarters of the plans referenced air quality guidance statements and performance measures, all MPO plans were likely concerned with air quality. Explicit air quality statements and measures could have been less common because of strong federal requirements for air quality conformity. Perhaps policy-makers—intentionally or unintentionally—discounted air quality concerns precisely because a mandated air quality assessment process already exists for long-range transportation planning. If true, this may suggest that federal planning requirements can skew regional priorities away from important areas like air quality. On the other hand, other regions might not have prioritized air quality if not for the federal mandate.

Regional plan policy foci are guided by national policy language. During our analyses, it appeared that regional guidance statements - in the selection of goals and objectives, or at least in their framing - were frequently influenced by national transportation policy language. Many plans referenced federal transportation "planning factors" established in SAFETEA-LU (reaffirmed in MAP-21 and expanded in the FAST Act): economic vitality, safety, security, accessibility/mobility, environmental protection, intermodal connectivity, operational efficiency, 
preservation, resiliency/reliability, and tourism (FAST Act, 2015). LRTP goals and objectives often matched these federal priorities or were borrowed almost verbatim.

Performance measurement is generally related to policy guidance. Based on our analysis, it does appear that performance measures are being related to guidance statements, as expected (Pickrell and Neumann, 2001). Overall, the frequency of health-related measures matched the relative frequency of health-related statements, although measures for physical activity and general health were lacking. In many plans, measures were clearly linked to goals or objectives in a table (Atlanta, Kansas City, Miami, San Francisco, St. Louis). It is assumed that performance measures are being developed to fit goals and objectives and not the other way around, although this cannot be determined without a longitudinal analysis of previous plans and more information on the plan development process. With new federal requirements for transportation performance measurement (MAP-21, 2012), the linkage of measures to goals becomes more critical.

Travel model forecasting capabilities for walking and bicycling do not appear to be strongly related to performance measures or guidance statements. Physical activity is the health component most directly linked to walking and bicycling levels. Recall that tier III models can estimate walk and bicycle travel while tier I models cannot. Notably, among those with performance measures, most plans from MPOs with tier III models (Los Angeles, Portland, San Francisco, Seattle, St. Louis) had physical activity measures; yet three of nine other plans (Atlanta, Houston, Kansas City) did too. Furthermore, only two MPO plans (Portland, San Francisco) reported using their tier III models for physical activity measurement. This suggests only a weak connection between model capabilities and performance measurement, the direction of causality of which cannot be determined. Did the measure provide the impetus for improving the model, or did model improvements allow for the adoption of the measure?

There seems to be an even weaker association between physical activity goals and walk/bicycle modeling: among the 12 plans with physical activity guidance statements, six were from MPOs with tier III models, while four were from MPOs with tier I models. As has been found in other studies (Handy, 2008), it appears that technical model capabilities lag changes to planning goals. The difficulty of travel models to adapt to new and broadening policy goals constrains analyses of transportation plans' effects in relation to their objectives. In turn, this may bias plan development and project prioritization in favor of factors that can be assessed using standard travel model outputs.

\subsection{Potential strategies}

Our findings highlight potential strategies for MPOs to more comprehensively consider transportation's impacts on health within long-range plans. With respect to guidance statements, plans could broaden their conceptualization of the health impacts of transportation. Concepts of traffic safety and air quality, while worthy goals on their own, could be reframed to emphasize their important roles on population health. Adopting guidance statements relating to increasing physical activity could add a positive tone to the typically-negative portrayal of transportation's health impacts. Discussions and analyses of accessibility could expand beyond job access to include affording access to healthy opportunities like recreation, health care, and full-service grocery stores. Plans could also benefit from language emphasizing a focus on those geographies and populations most affected by each component. Health could even be an overarching plan goal, with a definition encompassing safety, air quality, activity, and access aspects. Towards 
this end, education and outreach about transportation-health linkages might encourage the general public to demand a health goal and prompt regional officials to view other goals through a health lens. Community organizations, public health agencies, professional transportation societies, and academic research institutions are other possible sources for motivating changes (Lyons et al., 2012) to transportation policy statements.

Planning could also embrace more health-related performance measures, especially in the areas of physical activity and overall health. Ongoing travel model improvements around walking and bicycling (Broach et al., 2012; Clifton et al., 2016; Singleton and Clifton, 2013) should offer support for measures more closely related to physical activity levels (e.g., walking/bicycling durations, instead of trips or mode shares). A couple of plans contained performance measures related to walking and bicycling that did not meet the threshold of demonstrating a connection with "physical activity" or "health"; many of these measured amounts of walking and bicycling facilities. Making the leap from non-motorized facilities to walking and bicycling amounts or other physical activity measures could be low-hanging fruit for these MPOs. In addition, few plans assessed direct health outcomes, despite the transportation system's contributions to obesity, asthma, respiratory illness, lung cancer, and other diseases. Post-processing tools such as ITHIM (Woodcock et al., 2009) could help plans move beyond crash statistics and emission volumes towards comprehensive health measures like disability-adjusted life years (DALYs), allowing a comparison of safety, air quality, and physical activity impacts. In fact, the ITHIM model has already been applied to scenarios in San Francisco’s LRTP using travel model outputs (Maizlish et al., 2013). The dearth of physical activity statements and measures in plans represents a major opportunity, since most health impact modeling studies (using tools like ITHIM) find the health benefits of increased physical activity (from even modest increases in walking/bicycling) dramatically outweigh by orders of magnitude any impacts from air pollution or traffic safety (Mueller et al., 2015).

Certainly, MPO agency staff must select performance metrics that can be easily measured using available data and that can be updated over time; this remains a barrier to be overcome with respect to health-related measures. Transportation practitioners and public health professionals could partner to collect more routine data on travel distances (in addition to trip counts) and to estimate minutes of active travel (for physical activity benefits) and vehicle miles traveled (for pollutant emissions), helping to support increased performance measurement. More nuanced performance measures that target geographies or populations-e.g., specific criteria pollutants, high crash corridors/intersections, low-income and minority residents and neighborhoods_-could also yield equitable benefits. While many accessibility goals discussed increasing access to various populations, few plans included these types of population-specific measures. Increases in models and data could support more equitable measures not just of access but also of safety, air pollution, and physical activity.

On the topic of performance monitoring, MAP-21 requires states and MPOs to soon establish targets for nationally-identified performance measures in the goal areas of highways, safety, air quality, and freight (MAP-21, 2012); accessibility and especially physical activity are conspicuously missing. Because many regions take cues from federal policy, a national transportation health planning factor, goal, or measure could be a strategy to encourage MPOs to more strongly consider health in transportation planning and promote innovations in metrics and modeling. At the same time, our analysis showed that select regions are already putting human health concerns alongside other goals like congestion reduction, economic development, and 
environmental protection. Without a federal health performance measure, it remains to be seen whether MPOs will maintain existing or adopt new health-related measures.

Although our analysis did not address equity or public involvement in the transportation planning process, other research suggests improvements to public participation and environmental justice efforts may also increase health consideration. Local community backlash against major projects, including roadway expansions in low-income and minority communities, often revolve around inherent conflicts between regional goals (e.g., mobility, economic development) and local issues like health, safety, air quality, and accessibility (Lowe, 2011; McAndrews and Marcus, 2014). Such EJ conflicts could be a symptom of inadequate public participation in the planning processes (e.g., LRTP development): community members may prioritize health and livability goals but not be motivated to participate until they feel the impacts of a specific project (Innes and Booher, 2004), contributing to the sense that regional priorities are immutable (McAndrews and Marcus, 2014). Although there is no guarantee that communities' voices will be heard or their concerns adopted (Innes and Gruber, 2005), grassroots outreach efforts could help to engage citizens in transportation planning processes. Additionally, EJ analyses are moving beyond identifying relevant socio-demographic user groups towards improved equity and accessibility metrics (Golub and Martens, 2014; Karner and Niemeier, 2013), which could support health-related performance measures.

Finally, there are a number of other ways in which metropolitan transportation planning practice and transportation professionals can consider health impacts and improve health outcomes. Some of these planning actions include supporting health impact assessments, adopting health-relevant policies, and establishing regional health or bicycle/pedestrian plans, coordinators, and committees (Handy and McCann, 2011). Contingent on data and resources, these actions could comprehensively consider transportation's health impacts, from traffic safety, air quality, physical activity, and accessibility. Other strategies go beyond planning, such as: improving roadway design through Complete Streets, traffic calming, and bicycle/pedestrian infrastructure; reducing emissions via cleaner fuels and more fuel efficient passenger and freight vehicles; tightening safety laws around distracted and impaired driving, driver licensure, and seat belts; and many more (Ragland and Orrick, 2011; USDOT and CDC, 2015). While this study focused on preventative health approaches, there are also post-incident opportunities to improve health outcomes through transportation in the areas of emergency management and disaster relief. Such broader efforts require motivation on the part of MPO boards and staff, outreach to public health agencies, communication with other groups and the public, organizational relationship- and capacity-building, and other structural changes that need commitments over time (Lyons et al., 2012).

\subsection{Limitations and future work}

This review was not without limitations and challenges. Broadly, the MPO LRTP content analysis was the result of our understanding of plan language and relationships, informed by our own experiences and biases. Several steps involved subjective judgements, especially the identification and classification of guidance statements and performance measures, so other researchers may come to slightly different conclusions. Accessibility was particularly difficult to assess due to its broad scope. Also, transportation plans could have considered health less explicitly. In addition, our LTRP scan looked at a limited number of large MPOs. Conducting a census of large, medium, and small MPOs may yield more definitive conclusions and highlight 
innovative health-related practices not documented here. While smaller MPOs may lack some of the more advanced technical modeling capabilities useful for health analysis, their size may allow them to more flexibly and rapidly implement new approaches to considering transportation and health. Finally, long-range planning processes take years to complete, so an analysis of adopted plans may slightly lag current MPO practice and thinking. Nevertheless, this analysis was useful in describing recent-to-current practice.

Furthermore, our work suggests interesting areas for future research on how and why health is considered in metropolitan transportation planning, and the impacts of doing so in a more comprehensive way. Health-related guidance statements and performance measures do not appear in transportation plans overnight. Tracking the evolution of a region's LRTPs from one to the next could shed light on their development, including when, why, and how health concerns became an integral part of plans. Similarly, in-depth case studies and qualitative interviews with key participants (á la Lyons et al., 2012) may be better able to investigate the introduction and maturation of health within the plan development process, including the influences of public involvement and the statewide policy context.

On the other hand, simply including health in long-range transportation plans may or may not yield changes to transportation investments or improvements in health. It would be useful to investigate health's role in project prioritization, transportation improvement program development, and planning and engineering design requirements; and to relate the prevalence of guidance statements and performance measures to spending on specific types of projects (e.g., transit, bicycling, walking) or health metrics (e.g., obesity or asthma rates), especially with the rise of performance-based planning. Regions may have different health challenges: it would also be interesting to relate specific transportation-related health outcomes (e.g., non-motorized traffic fatality rates; the transportation sector's relative contribution to regional air pollution) to the emphasis these components are given in LRTPs.

Despite these challenges and opportunities, our content analysis valuably documents the state of the practice of considering health in long-range transportation plans, including the connections between guidance statements and performance measures. Other agencies may borrow performance measures presented herein or use sample health policy guidance statements to inspire MPO boards and the public to adopt, revise, or at least consider regional health goals and objectives. The findings and potential strategies in this paper offer a jumping off point for future improvements to the consideration of health within metropolitan transportation planning.

\section{Acknowledgements}

This work was made possible in part by a graduate fellowship from the Dwight David Eisenhower Transportation Fellowship Program, grant DTFH64-13-G-00011. The funder had no involvement in this research. The paper also benefitted from the suggestions of multiple anonymous reviewers.

\section{References}

American Association of State Highway and Transportation Officials (AASHTO), 2010. Highway safety manual (1st ed.). AASHTO, Washington, DC. 
(http://www.highwaysafetymanual.org/) (accessed 05.06.2014).

American Public Health Association (APHA), 2009. At the intersection of public health and transportation: Promoting healthy transportation policy. APHA, Washington, DC.

(https://www.apha.org/ /media/files/pdf/fact\%20sheets/at_the_intersection_public_health_an d_transportation.ashx) (accessed 31.03.2014).

Bell, J., Cohen, L., 2009a. The transportation prescription: A summary of findings and a framework for action, in Malekafzali, S. (Ed.), Healthy, equitable transportation policy: Recommendations and research. PolicyLink and Prevention Institute, Oakland, CA. (http://www.policylink.org/sites/default/files/HEALTHTRANS_FULLBOOK_FINAL.PDF) (accessed 31.03.2014)

Bell, J., Cohen, L., 2009b. Health effects of transportation policy, in Malekafzali, S. (Ed.), Healthy, equitable transportation policy: Recommendations and research. PolicyLink and Prevention Institute, Oakland, CA. (http://www.policylink.org/sites/default/files/HEALTHTRANS_FULLBOOK_FINAL.PDF) (accessed 31.03.2014)

Broach, J., Dill, J., Gliebe, J., 2012. Where do cyclists ride? A route choice model developed with revealed preference GPS data. Transp. Res. Part A: Policy Pract. 46 (10), 1730-1740. DOI: $10.1016 /$ j.tra.2012.07.005

Burbidge, S.K., 2010. Merging long range transportation planning with public health: A case study from Utah’s Wasatch Front. Prev. Med. 50 (Suppl.), S6-S8. DOI: 10.1016/j.ypmed.2009.07.024

Cambridge Systematics, Inc., 2000. A guidebook for performance-based transportation planning (NCHRP Report 446). Transportation Research Board, Washington, DC. Retrieved from (http://onlinepubs.trb.org/onlinepubs/nchrp/nchrp_rpt_446.pdf) (accessed 05.06.2014).

Cambridge Systematics, Inc., 2002. Technical methods to support analysis of environmental justice issues: Final report (NCHRP Project 8-36(11)). Transportation Research Board, Washington, DC. (http://onlinepubs.trb.org/onlinepubs/nchrp/docs/NCHRP0836(11)_FR.pdf) (accessed 06.06.2014).

Centers for Disease Control and Prevention (CDC), 2014. Healthy places: Transportation and health. CDC, Atlanta, GA. (http://www.cdc.gov/healthyplaces/healthtopics/transportation/default.htm) (accessed 23.03.2015)

CDC, 2016. Most recent asthma data. CDC, Atlanta, GA. (http://www.cdc.gov/asthma/most_recent_data.htm) (accessed 15.08.2016).

Clifton, K.J., Singleton, P.A., Muhs, C.D., Schneider, R.J., Lagerwey, P., 2016. Representing pedestrian activity in travel demand models: Framework and application. J. Transp. Geogr. 52, 111-122. DOI: 10.1016/j.jtrangeo.2016.03.009

Clean Air Act Amendments of 1990 (CAAA), 42 U.S.C. § 7506, 2012.

Cohen, L., Srikantharajah, J., Mikkelsen, L., 2009. Traffic injury prevention: A 21st-century approach, in Malekafzali, S. (Ed.), Healthy, equitable transportation policy: Recommendations and research. PolicyLink and Prevention Institute, Oakland, CA. (http://www.policylink.org/sites/default/files/HEALTHTRANS_FULLBOOK_FINAL.PDF) (accessed 31.03.2014)

Committee for Determination of the State of the Practice in Metropolitan Area Travel Forecasting, 2007. Metropolitan travel forecasting: Current practice and future directions (TRB Special Report 288). Transportation Research Board, Washington, DC. 
(http://onlinepubs.trb.org/onlinepubs/sr/sr288.pdf) (accessed 27.05.2014).

Dannenberg, A.L., Ricklin, A., Ross, C.L., Schwartz, M., West, J., White, S., Wier, M.L., 2014. Use of health impact assessment for transportation planning: Importance of transportation agency involvement in the process. Trans. Res. Rec.: J. Transp. Res. Board 2452, 71-80. DOI: $10.3141 / 2452-09$

Deakin, E., 2007. Equity and environmental justice in sustainable transportation: Toward a research agenda, in Rietveld, P., Stough, R.R. (Eds.), Institutions and sustainable transport: Regulatory report in advanced economies. Northampton, MA: Edward Elgar Publishing, Northampton, MA, pp. 51-69. (https://escholarship.org/uc/item/9607n3t9) (accessed 05.06.2014).

Duthie, J., Cervenka, K., Waller, S.T., 2007. Environmental justice analysis: Challenges for metropolitan transportation planning. Trans. Res. Rec.: J. Transp. Res. Board 2013, 8-12. DOI: $10.3141 / 2013-02$

Environmental Protection Agency (EPA), 2014. MOVES (Motor Vehicle Emission Simulator). EPA, Washington, DC. (http://www.epa.gov/otaq/models/moves/index.htm) (accessed 19.05.2015).

Evenson, K.R., Satinsky, S.B., Rodríguez, D.A., Aytur, S.A., 2012. Exploring a public health perspective on pedestrian planning. Health Promot. Pract. 13 (2), 204-213. DOI: $10.1177 / 1524839910381699$

Exec. Order No. 12898 (E.O. 12898), 3 C.F.R. 7629, 1994.

Federal Highway Administration (FHWA), 2014. Health in transportation: Frequently asked questions. FHWA, Washington, DC.

(http://www.fhwa.dot.gov/planning/health_in_transportation/faq/) (accessed 23.03.2015)

Fixing America’s Surface Transportation Act (FAST Act), 23 U.S.C. §§ 134, 150, 2015.

Forkenbrock, D.J., Sheeley, J., 2004. Effective methods for environmental justice assessment (NCHRP Report 532). Transportation Research Board, Washington, DC.

(http://onlinepubs.trb.org/onlinepubs/nchrp/nchrp_rpt_532.pdf) (accessed 06.06.2014).

Garibay, V., Seaton, P., 2014. Health impact assessment: California's SB 375 and its impact on Kern County's disadvantaged unincorporated communities and low income urban neighborhoods. Leadership Council for Justice and Accountability, Fresno, CA. (http://www.hiaguide.org/hia/kern-county-regional-transportation-plan-and-sustainablecommunities-strategies) (accessed 19.05.2015).

Golub, A., Martens, K., 2014. Using principles of justice to assess the modal equity of regional transportation plans. J. Transp. Geogr. 41, 10-20. DOI:10.1016/j.jtrangeo.2014.07.014

Grant, M., D’Ignazio, J., Bond, A., McKeeman, A., 2013. Performance based planning and programming guidebook. U.S. Department of Transportation, Federal Highway Administration, Washington, DC. (http://www.fhwa.dot.gov/planning/performance_based_planning/pbpp_guidebook/) (accessed 05.06.2014).

Grant, M., McKeeman, A., Bowne, B., Bond, A., Bauer, J., LaSut, L., ... D’Ignazio, J., 2014. Model long-range transportation plans: A guide for incorporating performance-based planning. U.S. Department of Transportation, Federal Highway Administration, Washington, DC. (http://www.fhwa.dot.gov/planning/performance_based_planning/mlrtp_guidebook/) (accessed 30.09.2014).

Handy, S., 2008. Regional transportation planning in the US: An examination of changes in technical aspects of the planning process in response to changing goals. Transp. Policy 15 
(2), 113-126. DOI: 10.1016/j.tranpol.2007.10.006

Handy, S., 2009. Walking, bicycling, and health, in Malekafzali, S. (Ed.), Healthy, equitable transportation policy: Recommendations and research. PolicyLink and Prevention Institute, Oakland, CA.

(http://www.policylink.org/sites/default/files/HEALTHTRANS_FULLBOOK_FINAL.PDF) (accessed 31.03.2014)

Handy, S., McCann, B., 2011. The regional response to federal funding for bicycle and pedestrian projects: An exploratory study. J. Am. Plan. Assoc. 77 (1), 23-38. DOI: 10.1080/01944363.2011.526537

Handy, S., McCann, B., Bailey, L., Ernst, M., McRee, L., Meharg, E., Ewing, R., Wright, K., 2009. The regional response to federal funding for bicycle and pedestrian projects (UCDITS-RR-09-15). Institute of Transportation Studies, University of California, Davis, CA. (http://escholarship.org/uc/item/26j7x815) (accessed 23.05.2014).

Health Effects Institute (HEI), 2010. Traffic-related air pollution: A critical review of the literature on emissions, exposure, and health effects (Special Report 17). HEI, Boston, MA. (http://pubs.healtheffects.org/view.php?id=334) (accessed 31.03.2014)

Howitt, A.M., Moore, E.M., 1999. Linking transportation and air quality planning: Implementation of the transportation conformity regulations in 15 nonattainment areas (EPA420-R-99-011). U.S. Environmental Protection Agency, Washington, DC. (http://www.epa.gov/oms/stateresources/transconf/generalinfo/fullrpt.pdf) (accessed 05.05.2014).

Hsieh, H.F., Shannon, S.E., 2005. Three approaches to qualitative content analysis. Qual. Health Res. 15 (9), 1277-1288. DOI: 10.1177/1049732305276687

Ingles, A., 2013. Incorporating health considerations into collaborative transportation decision making (Unpublished master’s thesis). Georgia Institute of Technology, Atlanta, GA. (https://smartech.gatech.edu/handle/1853/50412) (accessed 25.04.2014).

Innes, J.E., Booher, D.E., 2004. Reframing public participation: Strategies for the 21st century. Plan. Theory Prac. 5 (4), 419-436. DOI: 10.1080/1464935042000293170

Innes, J.E., Gruber, J., 2005. Planning styles in conflict: The Metropolitan Transportation Commission. J. Am. Plan. Assoc. 71 (2), 177-188. DOI: 10.1080/01944360508976691

Intermodal Surface Transportation Efficiency Act of 1991 (ISTEA), 23 U.S.C. §§ 101-512, 1994.

Karner, A., Niemeier, D., 2013. Civil rights guidance and equity analysis methods for regional transportation plans: A critical review of literature and practice. J. Transp. Geogr. 33, 126134. DOI: 10.1016/j.jtrangeo.2013.09.017

Lee, R.J., Sener, I.N., 2016. Transportation planning and quality of life: Where do they intersect? Trans. Policy 48, 146-155. DOI: 10.1016/j.tranpol.2016.03.004

Litman, T., 2013. Transportation and public health. Annu. Rev. Public Health 34, 217-233. DOI: 10.1146/annurev-publhealth-031912-114502

Lowe, K., 2011. Neighborhood, city, or region: Deconstructing scale in planning frames. Berkeley Plan. J., 24 (1), 46-63. (https://escholarship.org/uc/item/77w645rx) (accessed 23.03.2015).

Lyons, W., 2014. Together, better, smarter, safer: Planning for a healthy community. Presented at the New Partners for Smart Growth Conference, Denver, CO. (http://newpartners.org/2014/wp-content/plugins/scheduleviewer/data/presentations/Saturday/1.45- 
3.15pm/Together\%20Better\%20Smarter\%20Safer/Lyons.pdf) (accessed 25.04.2014).

Lyons, W., Peckett, H., Morse, L., Khurana, M., Nash, L., 2012. Metropolitan area transportation planning for healthy communities (FHWA-HEP-13-006). U.S. Department of Transportation, Research and Innovative Technology Administration, John A. Volpe National Transportation Systems Center, Washington, DC.

(http://www.planning.dot.gov/documents/Volpe_FHWA_MPOHealth_12122012.pdf) (accessed 25.04.2014).

Lyons, W., Morse, L., Nash, L., Strauss, R., 2014. Statewide transportation planning for healthy communities (FHWA-HEP-14-028). U.S. Department of Transportation, Research and Innovative Technology Administration, John A. Volpe National Transportation Systems Center, Washington, DC.

(http://www.planning.dot.gov/documents/VolpeFHWA_DOT_Health.pdf) (accessed 25.04.2014).

Maizlish, N., Woodcock, J., Co, S., Ostro, B., Fanai, A., Fairley, D., 2013. Health cobenefits and transportation-related reductions in greenhouse gas emissions in the San Francisco Bay Area. Am. J. Public Health 103 (4), 703-709. DOI: 10.2105/AJPH.2012.300939

Malekafzali, S. (Ed.), 2009. Healthy, equitable transportation policy: Recommendations and research. PolicyLink and Prevention Institute, Oakland, CA.

(http://www.policylink.org/sites/default/files/HEALTHTRANS_FULLBOOK_FINAL.PDF) (accessed 31.03.2014)

Manaugh, K., Badami, M.G., El-Geneidy, A.M., 2015. Integrating social equity into urban transportation planning: A critical evaluation of equity objectives and measures in transportation plans in North America. Transp. Policy 37, 167-176. DOI: 10.1016/j.tranpol.2014.09.013

Martens, K., Golub, A., Robinson, G., 2012. A justice-theoretic approach to the distribution of transportation benefits: Implications for transportation planning practice in the United States. Transp. Res. A 46, 684-695. DOI: 10.1016/j.tra.2012.01.004

Metro, 2014. Regional active transportation plan: Public review draft. Metro, Portland, OR. (http://www.oregonmetro.gov/public-projects/regional-transportation-decisions/2014-rtp) (accessed 05.06.2014).

McAndrews, C., Marcus, J., 2014. Community-based advocacy at the intersection of public health and transportation: The challenges of addressing local health impacts within a regional policy process. J. Plan. Educ. Res. 34 (2), 190-202. DOI: 10.1177/0739456X14531624

Moving Ahead for Progress in the 21st Century Act (MAP-21), 23 U.S.C. §§ 134, 150, 2012.

Mueller, N., Rojas-Rueda, D., Cole-Hunter, T., de Nazelle, A., Dons, E., Gerike, R., ... Nieuwenhuijsen, M., 2015. Health impact assessment of active transportation: A systematic review. Prev. Med. 76, 103-114. DOI: 10.1016/j.ypmed.2015.04.010

National Environmental Policy Act of 1969 (NEPA), 42 U.S.C. § 4321-4370h, 2012.

National Highway Traffic Safety Administration (NHTSA), 2016. Quick Facts 2014. NHTSA, Washington, DC. (https://crashstats.nhtsa.dot.gov/Api/Public/ViewPublication/812234) (accessed 15.08.2016).

Norton, P.D., 2008. Fighting traffic: The dawn of the motor age in the American city. MIT Press, Cambridge, MA.

Ogden, C.L., Carroll, M.D., Kit, B.K., Flegal, K.M., 2014. Prevalence of childhood and adult obesity in the United States, 2011-2012. J. Am. Med. Assoc. 311 (8), 806-814. DOI:

10.1001/jama.2014.732 
Peckett, H., Duffy, C., 2012. Best planning practices: Metropolitan transportation plans. US Department of Transportation, Research and Innovative Technology Administration, John A. Volpe National Transportation Systems Center, Washington, DC.

(http://www.planning.dot.gov/documents/BestPlanningPractices_MTP.pdf) (accessed 27.05.2014).

Pickrell, S., Neumann, L., 2001. Use of performance measures in transportation decision making. Performance measures to improve transportation systems and agency operations (Conference Proceedings 26). National Academy Press, Washington, DC. (http://onlinepubs.trb.org/onlinepubs/conf/reports/cp_26.pdf) (accessed 27.04.2014).

Ragland, D.R., Orrick, P., 2011. Transportation and health: Policy interventions for safer, healthier people and communities. Safe Transportation Research and Education Center, Berkeley, CA. (http://www.prevent.org/Transportation/) (accessed 25.08.2016)

Ross, C.L., Elliott, M.L., Rushing, M.M., Barringer, J., Smith, S., Frackelton, A., ... West, A., 2012. Health impact assessment of Atlanta Regional Plan 2040. Center for Quality Growth and Regional Development, Atlanta, GA. (http://www.cqgrd.gatech.edu/research/atlantaregional-plan-2040-health-impact-assessment) (accessed 19.05.2015).

Safe, Accountable, Flexible, Efficient Transportation Equity Act: A Legacy for Users (SAFETEA-LU), 23 U.S.C. § 134, 2005.

Singleton, P.A., Clifton, K.J., 2013. Pedestrians in regional travel demand forecasting models: State of the practice. Presented at the 92nd Annual Meeting of the Transportation Research Board (TRB), Washington, DC. (http://trid.trb.org/view/2013/C/1242847) (accessed 06.05.2014).

U.S. Department of Transportation (USDOT), 2007. The transportation planning process: Key issues (FHWA-HEP-07-039). USDOT, Washington, DC. (http://www.planning.dot.gov/documents/briefingbook/bbook.htm) (accessed 04.05.2014).

USDOT, 2014. Metropolitan planning organization (MPO) database. USDOT, Washington, DC. (https://www.planning.dot.gov/mpo.asp) (accessed 04.05.2014).

USDOT, CDC, 2015. Transportation and health tool. USDOT, Washington, DC. (https://www.transportation.gov/transportation-health-tool) (accessed 25.08.2016)

Washington, S., van Schalkwyk, I., Mitra, S., Meyer, M., Dumbaugh, E., Zoll, M., 2006. Incorporating safety into long-range transportation planning (NCHRP Report 546). Transportation Research Board, Washington, DC. (http://onlinepubs.trb.org/onlinepubs/nchrp/nchrp_rpt_546.pdf) (accessed 27.05.2014).

Weiner, E.,2013. Urban transportation planning in the United States: History, policy, and practice. Springer, New York, NY.

Woodcock, J., Edwards, P., Tonne, C., Armstrong, B.G., Ashiru, O., Banister, D., ... Roberts, I., 2009. Public health benefits of strategies to reduce greenhouse-gas emissions: Urban land transport. The Lancet, 374 (9705), 1930-1943. DOI: 10.1016/S0140-6736(09)61714-1

World Health Organization (WHO), 2014. WHO/Europe Health Economic Assessment Tool (HEAT). WHO, Copenhagen, DK. (http://www.heatwalkingcycling.org/) (accessed 19.05.2015). 


\section{References for long-range transportation plans}

Alamo Area Metropolitan Planning Organization, 2014. Mobility 2040. Alamo Area Metropolitan Planning Organization, San Antonio, TX.

(http://www.alamoareampo.org/Plans/MTP/index.html) (accessed 26.05.2015).

Atlanta Regional Commission, 2014. Volume 1: PLAN 2040 Regional Transportation Plan (RTP). Atlanta Regional Commission, Atlanta, GA. (http://www.atlantaregional.com/plan2040) (accessed 23.05.2014).

Baltimore Regional Transportation Board, 2011. Plan It 2035. Baltimore Regional Transportation Board, Baltimore, MD. (http://www.baltometro.org/plans/plan-it-2035) (accessed 23.05.2014).

Boston Region Metropolitan Planning Organization, 2015. Charting Progress to 2040: LongRange Transportation Plan of the Boston Region Metropolitan Planning Organization. Boston Region Metropolitan Planning Organization, Boston, MA. (http://bostonmpo.org/lrtp) (accessed 07.08.2015).

Chicago Metropolitan Agency for Planning, 2014. GO TO 2040: Plan Update Summary. Chicago Metropolitan Agency for Planning, Chicago, IL. (http://www.cmap.illinois.gov/about/2040) (accessed 26.05.2015).

Denver Region Council of Governments, 2011. 2035 Metro Vision Regional Transportation Plan. Denver Region Council of Governments, Denver, CO. (https://drcog.org/programs/transportation-planning/regional-transportation-plan) (accessed 07.08.2015).

East-West Gateway Council of Governments, 2015. Conneted2045: Long-Range Transportation Plan for the St. Louis Region. East-West Gateway Council of Governments, St. Louis, MO. (http://www.ewgateway.org/trans/longrgplan/longrgplan.htm) (accessed 07.08.2015).

Houston-Galveston Area Council, 2015. Bridging Our Communities: 2040 RTP. HoustonGalveston Area Council, Houston, TX. (http://www.h-gac.com/taq/plan/2040/) (accessed 26.05.2015).

Maricopa Association of Governments, 2014. 2035 Regional Transportation Plan. Maricopa Association of Governments, Phoenix, AZ. (https://www.azmag.gov/Projects/Project.asp?CMSID2=1126\&MID=Transportation) (accessed 07.08.2015).

Memphis Urban Area Metropolitan Planning Organization, 2012. Memphis Urban Area Long Range Transportation Plan: Direction 2040. Memphis Urban Area Metropolitan Planning Organization, Memphis, TN. (http://www.memphismpo.org/plans/long-range-plan-lrtp) (accessed 23.05.2014).

Metro, 2014. 2014 Regional Transportation Plan. Metro, Portland, OR. (http://www.oregonmetro.gov/public-projects/regional-transportation-decisions/2014-rtp) (accessed 21.07.2014).

MetroPlan Orlando, 2014. 2040 Long Range Transportation Plan: Plan Overview. MetroPlan Orlando, Orlando, FL. (http://www.metroplanorlando.com/plans/long-range-transportationplan/) (accessed 26.05.2015).

Metropolitan Transportation Commission, 2013. Plan Bay Area: Strategy for a Sustainable Region. Metropolitan Transportation Commission, Oakland, CA. (http://www.mtc.ca.gov/planning/plan_bay_area/) (accessed 05.06.2014). 
Miami-Dade Metropolitan Planning Organization, 2014. Miami-Dade 2040 Long Range Transportation Plan. Miami-Dade Metropolitan Planning Organization, Miami, FL. (http://www.miamidade2040lrtp.com/final-plan/) (accessed 26.05.2015).

Mid-America Regional Council, 2015. Transportation Outlook 2040: Metropolitan Kansas City’s Long-Range Transportation Plan. Mid-America Regional Council, Kansas City, MO. (http://www.to2040.org/) (accessed 18.08.2015).

Nashville Area Metropolitan Planning Organization, 2010. 2035 Nashville Area Regional Transportation Plan. Nashville Area Metropolitan Planning Organization, Nashville, TN. (http://www.nashvillempo.org/plans_programs/rtp/2035_rtp.aspx) (accessed 23.05.2014).

National Capital Region Transportation Planning Board, 2012. The Financially Constrained Long-Range Transportation Plan for the National Capital Region. National Capital Region Transportation Planning Board, Washington, DC. (http://www.mwcog.org/clrp/) (accessed 23.05.2014).

New York Metropolitan Transportation Council, 2013. Plan 2040: A Shared Vision for Sustainable Growth. New York Metropolitan Transportation Council, New York, NY. (http://www.nymtc.org/aboutrtp.cfm) (accessed 07.08.2015).

Northeast Ohio Areawide Coordinating Agency, 2013. connections+ 2035: Northeast Ohio’s Long-Range Transportation Plan. Northeast Ohio Areawide Coordinating Agency, Cleveland, OH. (http://www.noaca.org/index.aspx?page=71) (accessed 23.05.2014). Puget Sound Regional Council, 2009. VISION 2040. Puget Sound Regional Council, Seattle, WA. (http://www.psrc.org/growth/vision2040) (accessed 23.07.2014).

Puget Sound Regional Council, 2014. Transportation 2040. Puget Sound Regional Council, Seattle, WA. (http://www.psrc.org/transportation/t2040) (accessed 23.07.2014).

Regional Transportation Commission of Southern Nevada, 2013. Regional Transportation Plan: 2013-2035. Regional Transportation Commission of Southern Nevada, Las Vegas, NV. (http://www.rtcsnv.com/planning-engineering/transportation-planning/2013-2035-regionaltransportation-plan-update/) (accessed 07.08.2015).

Southeast Michigan Council of Governments, 2013. Creating Success with Our Transportation Assets: 2040 Regional Transportation Plan for Southeast Michigan. Southeast Michigan Council of Governments, Detroit, MI.

(http://www.semcog.org/ProgramsProjects.aspx?id=90136) (accessed 23.05.2014).

Southeastern Wisconsin Regional Planning Commission, 2014. Review and Update of the Year 2035 Regional Transportation Plan (Memorandum Report No. 215). Southeastern Wisconsin Regional Planning Commission, Waukesha, WI. (http://www.sewrpc.org/SEWRPC/Transportation/RTSPUpdate2014.htm) (accessed 18.08.2015).

Southern California Association of Governments, 2012. 2012-2035 Regional Transportation Plan/Sustainable Communities Strategy. Southern California Association of Governments, Los Angeles, CA. (http://rtpscs.scag.ca.gov/) (accessed 07.08.2015).

Southwestern Pennsylvania Commission, 2011. 2040 Transportation and Development Plan for Southwestern Pennsylvania. Southwestern Pennsylvania Commission, Pittsburgh, PA. (http://www.spcregion.org/trans_lrp.shtml) (accessed 23.05.2014). 